This item was submitted to Loughborough's Research Repository by the author.

Items in Figshare are protected by copyright, with all rights reserved, unless otherwise indicated.

\title{
Teamworking and Lean revisited: a reply to Carter et al.
}

\section{PLEASE CITE THE PUBLISHED VERSION}

http://dx.doi.org/10.1080/09585192.2015.1111252

\section{PUBLISHER}

(c) Taylor and Francis

\section{VERSION}

AM (Accepted Manuscript)

\section{PUBLISHER STATEMENT}

This work is made available according to the conditions of the Creative Commons Attribution-NonCommercialNoDerivatives 4.0 International (CC BY-NC-ND 4.0) licence. Full details of this licence are available at: https://creativecommons.org/licenses/by-nc-nd/4.0/

\section{LICENCE}

CC BY-NC-ND 4.0

\section{REPOSITORY RECORD}

Procter, Stephen, and Zoe J. Radnor. 2019. "Teamworking and Lean Revisited: A Reply to Carter Et Al.". figshare. https://hdl.handle.net/2134/20596. 


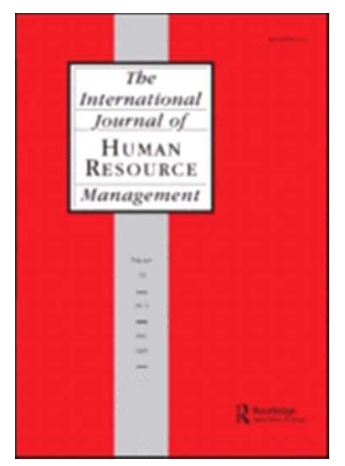

Teamworking and Lean in UK Public Services Revisited: A Reply to Carter et al.

\begin{tabular}{|r|l|}
\hline Journal: & The International Journal of Human Resource Management \\
\hline Manuscript ID & RIJH-2015-0791 \\
\hline Manuscript Type: & Original paper \\
\hline Keywords: & Lean, teamworking, teams, public services, HMRC, UK \\
\hline \multicolumn{2}{l}{} \\
\hline
\end{tabular}

SCHOLARONE ${ }^{\text {m }}$

Manuscripts 


\title{
TEAMWORKING AND LEAN IN UK PUBLIC SERVICES REVISITED:
}

\section{A REPLY TO CARTER ET AL.}

\begin{abstract}
This paper is a reply to Carter et al.'s (2015) response to an earlier paper of ours in this journal on the subject of teamworking under Lean in UK public services (Procter and Radnor, 2014). Our reply covers the following issues which Carter et al. have raised: the literature we used to structure our findings; the way in which we used concepts such as autonomy and teamworking; our research methods and approach; how Carter et al.'s newly available data on teamworking might be interpreted; and how data drawn from an official employee attitude survey might best be understood. On the basis of this we conclude that Carter et al.'s paper fails to meet its objectives. On some things the authors are simply wrong; on others, they grossly misrepresent our position; on still others, their interpretations are, at best, highly questionable.
\end{abstract}

\section{Introduction}

This paper is written in reply to Carter et al.'s (2015) response to the paper of ours (Procter and Radnor, 2014) that appeared last year as part of a special issue of The International Journal of Human Resource Management on the subject of lean management. Our paper used a study of Her Majesty's Revenue \& Customs (HMRC) to examine the operation of teamworking in the context of a lean environment. We found that some evidence existed for a worsening of employees' working conditions, and they also had little opportunity to be involved in improvement activity. At the same time, the experience of Lean amongst employees was not unequivocally negative, with the operation of work teams in HMRC 
seeming to provide one way in which the increased demands made on employees might be accommodated.

As part of the attempt to draw the wider implications of these findings, we set them against what Carter et al. had found in their study of Lean in the same organization (Carter et al., 2011a, 2011b, 2013a, 2013b). Our argument here was that Carter et al. had taken little or no account of the way in which teamworking operated in HMRC, and that, had they done so, then it might have been easier to understand the differences between their findings and ours - and also between their findings and the results of an official employee survey undertaken at around the same time (Civil Service People Survey, 2011).

Carter et al.'s response to our paper (Carter et al., 2015) can be found elsewhere in this issue of The International Journal of Human Resource Management. It can be seen from this that rather than engage with the points we made about their work and try to understand how any differences might best be understood, Carter et al. mount a full-scale defence of their position and full-scale attack on ours. As this reply to their paper will demonstrate, they do not make a very good job of this. On some points they are simply wrong; on others, they grossly misrepresent what our paper said; on still others, their interpretations are, at the very least, highly questionable.

Our reply to Carter et al. follows roughly the structure (though not the section headings) of their response. We thus cover the following main issues: the literature we used to structure our original findings; the way in which we used concepts such as autonomy and teamworking; our research methods and approach; how Carter et al.'s newly available data on teamworking in HMRC might be interpreted; and how the data drawn from the Civil Service People Survey might best be understood. In conclusion, we bring these things together and try to make some sense of the position that Carter et al. have taken. 


\section{The "missing literature"}

We turn first, therefore, to the claim of Carter et al. (2015: 3) that we deliberately avoid reference to 'a body of largely [sic] well-known critical work on lean'. This body of work is said to be made up of the following: Danford, 1998; 1999; Delbridge, 1998; Landsbergis et al., 1999; Lewchuk and Robertson, 1997; Mehri, 2006; Sprigg and Jackson, 2006; Sprigg et al., 2007; and Stewart et al., 2009. There are a number of things that need to be said about this. The first is to question the extent to which these books and articles together constitute a cohesive 'body' of work in the way that Carter et al. claim. If we look at some of these works individually, we can note, for example, that Sprigg et al. (2007) contains no mention at all of lean management. Delbridge's (1998) book is concerned with how employees work under Lean, but it is at least questionable whether it takes the line that Carter et al. attribute to it (see Procter, 2001). Equally, while Mehri (2006) might be considered to be sufficiently 'critical', its focus is on product development rather than core operations. Other references on the list might be argued over, but it still seems something of an overstatement to describe these items taken together in the way that Carter et al. do- especially when the first item, 'Danford (1998)', seems not to exist at all.

It also seems that our non-inclusion of these references comes as much more of a shock and an affront to Carter et al. than it would to anyone else. To illustrate this, we look at the seven other articles on lean management contained in the special issue of International Journal of Human Resource Management. These also make little use of the references that Carter et al. recommend. Of the seven articles, only one (de Koeijer et al., 2014) contained as many as three of the eight references in Carter et al.'s list, one (Cullinane et al., 2014) contained two, two articles (Bouville and Alis, 2014; Thirkell and Ashman, 2014) contained one each, and three (Lindsay et al., 2014; Sparrow and Otaye-Ebede, 2014; Stanton et al. 2014) contained 
none at all. Looking at the same thing from the point of view of the eight 'missing literature' items, then, out of seven potential citations from the special issue, only one item on the list (Landbergis et al., 1999) is cited as many as three times, only one (Stewart et al, 2009) has two citations, two items (Mehri, 2006; Sprigg and Jackson, 2006) have just one citation each, and the other four (Danford, 1999; Delbridge, 1998; Lewchuk and Robertson, 1997, Sprigg et al., 2007) have none at all. In sum, out of 56 possible citations (if all the seven papers in the special issue cited all eight available items on the recommended list) we have a grand total of seven. This is not, of course, to question the merits of the individual books and papers on Carter et al.'s list; it is merely to suggest that they do not together comprise such a central body of literature as Carter et al. claim.

Carter et al. might see in all this a grand conspiracy to suppress the 'truth' about Lean; the reality, however, is rather more prosaic. Rather than worrying about having to pass muster at some kind of bibliographic kit inspection, the choice of what literature to use - for us, and, presumably, for the other authors of papers in the special issue--will depend on the questions to which the paper is attempting to provide answers. Carter et al. clearly do not like the questions we are addressing (and they go so far as to provide a draft of a question they think we should be looking at (2015, note 4)), but they can hardly expect us not to use the literature we consider most relevant in attempting to provide answers to them. The central concerns of our paper was what teamworking might and does like look under Lean, but Carter et al. provide no real account of how consideration of the 'omitted' references might contribute to this. They describe the ways in which they claim that this literature portrays lean teams (Carter et al., 2015: 4), but provide no specific references to back this up. 
Indeed, Carter et al. themselves would barely meet the requirements that they are so keen to impose on others. If we look at the four papers of theirs (Carter et al., 2011a; 2011b; 2013a; 2013b) that we cite in our original article (Procter and Radnor, 2014), then only one of them (Carter et al., 2013b) cites the majority of the papers on their recommended reading list. Looked at from the other direction, only one paper from their list (Lewchuk and Robertson, 1997) is cited in all four of Carter et al.'s papers, and, one other (Mehri, 2006) is actually not cited in any of them.

In any case, if we had been so keen to avoid reference to work in what is identified as this 'critical' tradition, why would we not avoid reference to the work of Carter et al. themselves? Carter et al. (2015: 4) place their own work squarely in this tradition, but we cite four of their papers (Carter et al., 2011a; 2011b;2013a; 2013b) and address in a direct way the issues they raise - this is precisely what has generated their response. They might not like how we interpret their work, and they are, of course, quite entitled to respond to this interpretation. They cannot at the same time, however, accuse us of ignoring the approach of which it is part.

\section{Teamworking and lean: Some conceptual considerations}

A second main area of concern for Carter et al. is the concepts we (and they) use and the theoretical positions underlying them. What we get from them, however, is a very detailed but very muddled and ill-tempered critique of how we approach the contextualisation of our empirical findings. It is difficult to know where to start in all this, but let us take a deep breath and dive straight in. Carter et al. (2015: 3-4) say first that we somehow 'imply' that their labour process perspective has dictated their research findings. This seems to be based 
largely on our description of a labour process perspective as 'underpinning' their conclusions (Procter and Radnor, 2014: 2982).

Carter et al. are certainly very quick to take offence. They accuse us of portraying them as a labour process 'outlier' that 'stands “in contrast to" all other studies' (Carter et al., 2015: 4). The phrase 'in contrast to' is indeed taken from our paper (p. 2892), but it is clear that the contrast we refer to is between Lean's importance in HMRC and its more limited impact elsewhere in the public sector. But why, in any case, is referring to their paper as taking a labour process approach something to which they take exception? Quite apart from anything else, the paper of Carter et al.'s we focused on here (Carter et al. 2011b) is entitled '"All they lack is a chain",' a quote taken not from a research participant in HMRC but from a manager cited in Braverman's (1974: 336) Labor and Monopoly Capital.

Carter et al. (2015) are also very critical of our treatment of the idea of teamworking, but their claims are based on a bewildering misinterpretation of what we actually said. Carter et al. (2015: 5) offer a potted history of teamworking, distinguishing between the Lean and the socio-technical systems (STS) traditions. This allows them to accuse us of executing a 'conflation' of these traditions, something which Carter et al. (2015: 5) say creates for us 'an underlying theoretical problem'. The problem, apparently, is that we confuse 'autonomy' with 'empowerment'. Worker autonomy is a good thing from Carter et al.'s perspective; while empowerment, 'a classic term in the unitarist HRM lexicon' (Carter et al., p. 5), is not.

It must be very comforting to be able to make such a clear-cut and universally applicable distinction, but for many of us it is not so easy to do. The passage in our paper in which Carter et al. spot our supposed confusion is that which relates to the work of Vidal (2007) 
(Procter and Radnor, 2014: 2980). We use the term 'empowerment' here because this is the term that Vidal himself uses - and, in fact, apart from in reference to Vidal, we do not use the term at all in the paper. Now, whether, in Carter et al.'s terms, Vidal actually means 'empowerment' or whether he means 'autonomy', we can leave to them to judge. They might also look at one of the papers on their own list, Lewchuk and Robertson's (1997) 'Production without empowerment'. Is such production to be seen as a good thing or a bad thing?

\begin{abstract}
All this is not to say, of course, that we should have no regard to the meaning of terms; only that issues of definition can never be so clear-cut and universally applicable as Carter et al. suggest. Issues of precise definition might be important, but they cannot be central to every paper. We can see, even in the response of Carter et al. (2015), how they begin to tie themselves up in knots. Having distinguished between autonomy and empowerment, they then refer to 'genuine autonomy' (Carter et al., 2015: 5). What, then, is non-genuine autonomy?
\end{abstract}

Carter et al. (2015: 5-6) turn then to the question of how these things might play out in the context of lean teams, where they make objection to our use of the term 'indirect autonomy'. Our objective here was to convey the idea that employees might have some control over how they did their work, but, that rather than enjoying any day-to-day discretion, any control would be achieved through contributions to the development of new standardised working practices. We fully acknowledge in our paper how workers' scope in this regard might be severely circumscribed and even counter-productive (Procter and Radnor, 2980-2981), and it was not our intention to portray Lean as any kind of exemplary practice in regard to employee autonomy. Allowing for the logical possibility that this notion of autonomy might 
be extended hardly constitutes an heroic attempt to 'rescue' the idea of autonomy for Lean (Carter et al., p. 6).

Even more of a puzzle is how the idea of target-based teamworking, developed by one of us in an earlier study of HMRC's main predecessor organization (Procter and Currie, 2004), can be seen by Carter et al. (2015: 6) as a 'second rescue attempt' for autonomy. As our paper makes clear (Procter and Radnor, 2014: 2982), 'Procter and Currie found a form of teamworking in which autonomy played little part'. How teamworking had worked in this case, it was argued, '[was] through the collective responsibility that team members felt for meeting the team's work targets' (Procter and Radnor, 2014: 2982). Carter et al. (2015: 6) dismiss as a 'fallacy' the idea that 'team-based targets generate a tangible sense of collective teamworking', citing a piece of work in which they say targets did not act in this way (Baldry et al., 1998). How this in itself establishes the fallistic nature of the argument is not made clear; but, perhaps more importantly, we cannot in any case see how use of the idea of targetbased teamworking represents any kind of attempt to 'rescue' the idea of autonomy. If anything, the exact opposite is the case. Carter et al. (2015: 7) say that the work of van den Broek et al. (2004) is 'instructive' here-it is, but not for the reasons that Carter et al. think. There are, in fact, strong parallels between van den Broek et al.'s 'teams without teamwork' and what we might describe as Procter and Currie's 'teamworking without (much) autonomy'.

\section{Research methods and approach}

In Carter et al.'s (2015) third main area of concern, research methods and approach, they begin by providing an account of their motivations and the methods they used in their own research in HMRC (2015: 8-9). Quite why they do this is difficult to understand at first sight, 
since none of the assertions they are so anxious to make is a response to anything we said in our paper. They say, for example, that they were 'committed to giving expression to the experiences and voices of the marginalised agents within the dominant discourse (Carter et al., 2015: 8) and that '[this] orientation does not render our research problematic nor mean that our evidential basis is narrow' (Carter et al., 2015: 8), but this is not a direct response to anything in Procter and Radnor (2014). They say that we describe their interpretation as 'one-sided' (Carter et al., 2015: 9), but this expression, or anything like it, appears nowhere in our paper. We did say that their portrayal of Lean in HMRC is 'almost exclusively negative' (Procter and Radnor, 2014: 2992) but this was merely a description of what Carter et al. themselves are claiming.

In any case, Carter et al. seem to want it both ways. In seeking to give a voice to those marginalised in HMRC, they say, the purpose of their research 'was not [emphasis added] to chase elusive and unattainable universal truths of lean' (Carter et al., 2015: 8). Yet in the following paragraph (Carter et al., 2015: 9), their stress on the breadth, depth and objectivity of their research suggests that this is exactly what they are trying to do-especially if we are to take their work as part of the body of research that we are supposedly ignoring because of the 'truths' it has established about Lean.

These difficulties for Carter et al. arise in part because they want to make a distinction between their own 'unequivocally independent' research (Carter et al., 2015: 8) and the research upon which our paper was based, 'the degree of independence [of which],' they say (Carter et al., 215: 7), 'is open to question'. Again, while Carter et al.'s paper claims to be a response to ours, nowhere did we raise the question of the degree to which their research was independent. Clearly, however, they feel the need to defend themselves on this issue. What 
precisely is meant by independence in research is, of course, a huge issue in itself, but at the risk of over-simplification we can identify two different ways of looking at it. The first seems to be the degree to which the design and conduct of any project is shaped by the researcher rather than the researched. An 'unequivocal' independence would, in this sense, seem impossible to achieve. Instead, what needs to done is to be as clear as possible (or, perhaps, as clear as necessary) on the researcher-researched relationship and on how this might have shaped the research. Although not always expressed in these terms, this is how we could characterise the usual approach to these issues, and this is what we did in our own paper (Procter and Radnor, 2015: 2983-2987).

The second way of looking at independence would regard it as the capacity to avoid having deliberately to distort the research findings in order to make them acceptable to the sponsors of the research. Carter et al. (2015: 8) base their claim to have been 'unequivocally independent' on the fact that one of their papers contains criticism of the leadership of the trade union that had provided support for their research. Looking at things in this way raises some interesting questions. What, for example, would be the degree of criticism necessary in order to demonstrate independence? And would the absence of criticism be taken in itself as evidence of lack of independence? In the event, these are questions we do not have to address, since Carter et al. themselves later provide the evidence that allows us to reject any charges on this count. In being so keen to show that our findings are, in some respects, quite consistent with theirs in being critical of the impact of Lean in HMRC, they do at least succeed in undermining that part of their charge-sheet that accuses us of lack of independence (Carter et al., 2015: 12). At the same time this creates problems for their overall position, since it attempts to locate us simultaneously in thrall and in opposition to senior HMRC management, 
As for how data might be presented and interpreted, Carter et al. claim that the weight of evidence is in favour of a negative interpretation of Lean. As they show (Carter et al., 2015: 9), this is certainly true of the data generated from their questionnaire survey. This much is not in question. What they also object to, however, is the way we present and interpret our own data. They complain that we do not attach numbers or proportions of staff to particular views or attitudes (Carter et al., 2015: 9-10). There does not seem to be anything particularly remarkable in our doing this. As is clear in the paper, the bulk of our data was drawn from interviews with, and focus groups of, staff at a number of different HMRC sites. Carter et al. might not like the way in which the data was gathered (Carter et al., 2015: 8) but the way in which our analysis was carried out is entirely consistent with it. We make no claims to have obtained structured questionnaire responses from a statistically representative sample of HMRC staff, and it would have made no sense to analyse the data as if it were of this nature.

\section{Teamworking in HMRC}

Carter et al. (2015) also now provide us with some newly available data to consider. Almost without warning, on p. 11 of their paper, they produce a summary of responses to a series of questions they had asked employees about their experience of teamworking in HMRC. Quite why they have made so little use of it in their published work up to this point is not made clear (although see Carter et al., 2011b: 93); nor too is whether there is other data on which they have not yet drawn. Whatever the case, the chief concern of our original paper had been to understand the operation of teamworking in the context of Lean, and we welcome their attempt to make a contribution to this. An examination of the data, however, leaves us with a sense of frustration, since we are not provided with any detail on the design of the survey 
items. What constructs are the statements in Carter et al.'s (2015) Table 1 designed to capture? What conceptual framework underpins them? Have the same or similar statements been used in other studies? Why a four-fold scale for responses? Why these four descriptors? In the absence of such information, interpretation of the results can be tentative at best.

One particular issue is how Carter et al.'s survey captures change over time. Their Table 1 shows, for example, that the proportion of respondents who 'frequently' experience 'help received from team members' is $60 \%$ 'before' the introduction of Lean, and $26 \%$ 'after'. It seems from Carter et al.'s limited description that rather than these figures being based on two separate surveys, one carried out 'before' and the other 'after', those surveyed are asked to provide a 'before' and an 'after' response both at the same time. There are obvious, practical reasons why the data might have to be generated in this way, but the implications of asking this type of this type of question do at least have to be considered.

Carter et al. seem to be aware of these 'before and after' issues at a more general level. They recognise that in their attempts to highlight the adverse aspects of the 'after' situation, they might be accused of portraying the 'before' in too positive a light. Their purpose, they say (Carter et al., 2015: 11), 'is not [emphasis added] to present team working before lean as some white-collar idyllic craft'. The situation pre-Lean is portrayed as one in which 'whole case working' was the principle on which work was organized in HMRC (Carter et al., 2015: 11). This portrayal draws on the work of Fisher (2004), who describes a system in which each member of staff was allocated a certain number of cases, with the responsibility for working each of these cases from start to finish. Fisher examines an attempt in one part of a government agency (presumably the Inland Revenue, the main predecessor organization 
of HMRC) to replace this with a system in which work was allocated on the basis of the different tasks involved in each case.

Fisher's work is valuable here, but it is only one part of the overall picture. Carter et al. make no mention here of the work of one of us (carried out at roughly the same time as Fisher's) which examined the widespread introduction and operation of a team-based system of work organization in the Inland Revenue (Procter and Currie, 2004; Currie and Procter, 2003). This research, already referred to above (p. 7), shows how whole-case working (or 'individual allocations') was replaced by 'group allocations': in other words, cases were allocated not to individual employees but to groups or teams. It was then largely left to the teams (or at least to the team leaders) to decide how to divide up the work associated with their allocation. This discretion meant that some degree of whole-case working could be retained, but to describe the system as being essentially of this nature would be to ignore the widely-acknowledged effects of the introduction of group- or team-based allocations. The more general point, as we argued in our original paper (Procter and Radnor, 2014: 2993), is that any 'impact' of Lean will depend to some degree on the nature of the setting into which it is introduced. An understanding of the 'after', in other words, is likely to be enhanced by an understanding of the 'before'.

We accept that calls to Carter et al. to engage positively with this earlier work (let alone with Procter and Radnor, 2014) are unlikely to be heeded, since by this stage in their paper (2015: 12) they seem to have convinced themselves that our paper was motivated by an attempt to do them down. In an attempt to counter this, and based on reading our paper 'dispassionately', they point to how little evidence we provide to 'undermine' (Carter et al., 2015: 12) their case. 'On the contrary,' they say (Carter et al., 2015: 12), 'many of their 
quotes are quite consistent with our studies'. They point to the evidence we present on feelings of deskilling and on lack of involvement in the development of working practices. Our attempts then, apparently, to 'ameliorate the negative representation of lean' make our defence 'Maginot-like in its effectiveness' (Carter et al., 2015: 12). We 'undermine' our 'positive portrayal of teamworking' by quoting a member of HMRC staff who was dismissive of daily team meetings (Carter et al., 2015: 13).

\begin{abstract}
All this is straw-person argument of the crudest kind. Carter et al. set up our paper as aiming to act simultaneously as a cheer-leader for Lean and a direct assault on their own work. In neither respect can this claim be substantiated. What it does allow them to do, however, is to portray what we say as a failure to meet our objectives. We are 'unsuccessful' only if, as Carter et al. (2015: 15) assume, we were determined to 'extricate a positive message' from this data; or make a case 'for' lean teamworking. 'In sum,' they say, 'Procter and Radnor's evidence is strikingly contradictory' (Carter et al., 2015: 13). It clearly is to Carter et al., but only because of how they choose to portray our argument in the first place. Others, we are sure, are capable of making their own judgements.
\end{abstract}

\title{
The 2010 Civil Service People Survey
}

The fifth and final set of issues raised by Carter et al. concerns the interpretation of the 2010 Civil Service People Survey. We had used the survey in our paper as another source of data on employee attitudes to Lean and to teamworking. It was clear that it was incumbent on any interpretation of these things to at least to take the survey's results into account. Carter et al. are very defensive on this. They claim first of all that we 'misrepresent [their] use of this evidence by incorrectly stating that the Civil Service People Survey (CSPS) is cited in Carter et al. (2013a)' (Carter et al., 2015, p. 14). Carter et al. (2015) are simply 
wrong here. The reference contained in this (2013a) paper is a report of the Treasury Select Committee (2011), but Carter et al. seem to be under the impression that the committee undertook its own employee opinion survey across the civil service. In fact, the committee's report draws on the data generated by the Civil Service People Survey (see Treasury Select Committee, 2011: para. 42). If we go back to the original source, in other words, it is true, as we said, that this is the data on which Carter et al. rely.

It is, in fact, very difficult to understand what Carter et al. were trying to do with this survey - or even what they thought the survey was. In one of Carter et al.'s papers (2011a: 121) there is a Treasury Select Committee report cited as being a 2010 (rather than a 2011) publication, but this does not appear in the paper's list of references. It is not clear whether the date is wrong or whether this is a different report. Reference is made in Carter et al. (2011a) to a Guardian newspaper article on the subject, but the article does not seem to have appeared on the date that they cite. In their current paper, the citation again is of an unreferenced 2010 report from the Treasury Select Committee (Carter et al., 2015: 14), but their use of the CSPS data suggests that it is the 2011 report that they mean. The source of the description of the HMRC workforce as the 'most unhappy' of any government department (Carter et al., 2015:14) is thus not very clear--the 2011 report, in drawing on the CSPS data, refers generally to the level of 'engagement' of staff (Treasury Select Committee, 2011, paras 40-51). All in all, a rather confused picture emerges from what Carter et al. are trying to do with these sources.

\author{
Notwithstanding this, they now seem keen to engage with some of the detail of the CSPS, for \\ the survey apparently reveals 'potential errors' in our line of argument (Carter et al., \\ 2015: 14). We said in our original paper that the CSPS 'shows working as a member of a


team to be the most positive aspect of work amongst those surveyed in HMRC' (Procter and Radnor, 2015: 2993). This was not a huge claim, and, on the basis of the bald figures, it is not one that can easily be denied. Carter et al, however, are determined that even these figures have to be seen in a particular way. From the survey it can be seen that $82 \%$ of HMRC employees responded positively to the statement, 'The people in my team can be relied upon to help when things get difficult in my job'. For Carter et al. (2015: 14), in an echo of their earlier arguments about 'genuine' autonomy in organic teams, such figures 'reflect informal group and collegiate solidarity rather than technical questions of lean and teamworking'. Now, we can leave to one side questions of whether these two things can and should be seen as so distinct from each other, but we do need to ask what gives Carter et al. this insight into the minds of the respondents of the survey. Similarly, in explanation of the figure of $76 \%$ who responded positively to the statement, 'The people in my team can be relied upon to help when things get difficult in my job,' Carter et al. (2015: 15) say that this 'has to be seen in the context of the belief that this was despite senior management and lean working, not because of it'. The idea of '[having] to be seen in the context of' seems to have no meaning here beyond the contention that the figure of $76 \%$ should be disregarded because it does not tally with the conclusions at which Carter et al. have already arrived.

Carter et al. (2015: 15) also draw attention to a combination of data that suggests that HMRC employees regard front-line management in a more positive way than they do senior management. Quite what point Carter et al. are trying to make here is not clear, but we would accept that both our work and theirs might have placed greater emphasis on the role played by front-line and other middle-level managers. Carter et al. should, however, be aware of the implications of this. If front-line and other middle-level managers are to be looked at as more than just passive, downward communicators of the policies of their more 
senior colleagues - if, in other words, in line with other work on the role of middle managers (see eg Currie and Procter, 2005), they are to be recognised as being active agents in the implementation or translation of phenomena such as Lean — then this opens up a potentially important source of variation in the experience of employees, a variation whose mere existence Carter et al. are at such pains to deny.

\section{Conclusions}

It is difficult to see why Carter et al. have responded to our paper in the way that they have. Rather than address in a direct way what we actually said, they mount a full-scale defence of their own work and launch a full-scale attack on ours. As our response demonstrates, the attack is largely unsuccessful. On some things — what they say our paper said about their work, for example, or their use of the CSPS - they are simply wrong; on others - our use of certain concepts, our motivations and findings - they grossly misrepresent our position; on still others - the significance of the CSPS data, the nature of teamworking in HMRC before and after Lean - their interpretations are, at best, highly questionable.

Underpinning their response seems to be a certain measure of insecurity. Carter et al.'s (2015) identification with a labour process approach, their methods and motivations, the independence of their research, the danger of giving a rose-tinted picture of work in HMRC before Lean — on all these things they seem almost too eager to proclaim the strength of their position. A process of self-appraisal might have been welcome if it had resulted in an acknowledgement that in certain places their position was not so strong, and, with this acknowledgement, given rise to a desire, if not to effect reconciliation between their work and ours, then at least to recognise why differences in views existed and might persist. 
What we get instead, however, is a defensiveness which manifests itself in egocentrism and what can only be described as arrogance. The egocentrism is evident in Carter et al.'s apparent assumption that our paper was designed primarily as an attack on their work. Our paper looked at Lean in HMRC and, as such, it would have been perverse for it to have ignored the work of Carter et al. - and our findings did carry some more or less direct implications for them. In particular, we pointed to their neglect of analysis at the level of team - a point that, in now more fully producing and analysing data on the subject, they seem implicitly to acknowledge. Our primary concern in the paper, however, was to use the case of HMRC to explore more generally the relationship between Lean and teamworking.

The academic arrogance of Carter et al. is evident throughout their response to our paper. They feel they are in a position to say what secondary sources we should have used, what research questions we should have addressed, what research methods we should have employed, how the data should have been interpreted and what conclusions we should have come to. Our chief offence seems to be to have said something different to them on a subject they regard as their own property. Rather than constructive engagement, however, what they offer is little more than: 'we are right: you must be wrong'. This reply to their response is not offered in the same spirit, and we hope that it allows readers of both papers to arrive at their own conclusions.

\section{References}

Baldry, C., Bain, P., \& Taylor, P. (1998). Bright satanic offices: Intensification, control and 'team Taylorism'. In P. Thompson and C. Warhurst (eds), Workplaces of the Future (pp. 163-183). London: Palgrave Macmillan.

Bouville, G., \& Alis, D. (2014). The effects of lean organizational practices on employees' attitudes and workers' health: Evidence from France. The International Journal of Human Resource Management, 25, 3016-3037.

Braverman, H. (1974). Labor and Monopoly Capital: The Degradation of Work in the Twentieth Century. New York \& London: Monthly Review Press. 
Carter, B., Danford, A. Howcroft, D., Richardson, H., Smith, A., \& Taylor, P. (2011a). Lean and mean in the civil service: The case of processing in HMRC. Public Money and Management, 31, 115-122.

Carter, B., Danford, A. Howcroft, D., Richardson, H., Smith, A., \& Taylor, P. (2011b). ”All they lack is a chain": Lean and the new performance management in the British civil service. New Technology, Work and Employment, 26, 83-97.

Carter, B., Danford, A. Howcroft, D., Richardson, H., Smith, A., \& Taylor, P. (2013a). Taxing times: Lean working and the creation of (in)efficiencies in HM Revenue and Customs. Public Administration, 91, 83-97.

Carter, B., Danford, A. Howcroft, D., Richardson, H., Smith, A., \& Taylor, P. (2013b). "Stressed out of my box": Employee experience of lean working and occupational ill health in clerical work in the UK public sector. Work, Employment and Society, 27, 747-767.

Carter, B., Danford, A. Howcroft, D., Richardson, H., Smith, A., \& Taylor, P. (2015). Uncomfortable truths - Teamworking under lean in the UK. The International Journal of Human Resource Management, XX, xxx-xxx.

Civil Service People Survey 2010 (2011). https://data.gov.uk/dataset/civil-service-peoplesurvey-2010/.

Cullinane, S., Bosak, J., Flood, P., \& Demerouti, E. (2014). Job design under lean manufacturing and the quality of working life: A job demands and resources perspective. The International Journal of Human Resource Management, 25, 2996-3015.

Currie, G., \& Procter, S. (2003). The interaction of human resource management policies and practices with the implementation of teamworking. The International Journal of Human Resource Management, 14, 581-599.

Currie, G., \& Procter, S. (2005). The antecedents of middle managers' strategic contribution: The case of a professional bureaucracy. Journal of Management Studies, $42,1325-1356$.

Danford, A. (1999). Japanese Management Techniques and British Workers. London \& New York: Mansell.

Delbridge, R. (1998). Life on the Line in Contemporary Manufacturing: The Workplace Experience of Lean Production and the 'Japanese' Model. Oxford \& New York: Oxford University Press.

De Koeijer, R., Paauwe, J., \& Huijsman, R. (2014). Toward a conceptual framework for exploring multilevel relationships between lean management and six sigma, enabling HRM, strategic climate and outcomes in healthcare. The International Journal of Human Resource Management, 25, 2911-2925.

Fisher, M. (2004). The crisis of civil service trade unionism: A case study of call centre development in a civil service agency. Work, Employment and Society, 18, 157-177.

Landsbergis, P., Cahill, J., \& Schnall, P. (1999). The impact of lean production and related new systems of work organization on worker health. Journal of Occupational Health Psychology, 4, 108-130.

Lewchuk, W., \& Robertson, D. (1997). Production without empowerment: Work reorganization from the perspective of motor vehicle workers. Capital and Class, 19, 37-64.

Lindsay, C., Commander, J., Findlay, P., Bennie, M., Corcoran, E., \& Van Der Meer, R. (2014). "Lean", new technologies and employment in public health services: Employees' experiences in the National Health Service. The International Journal of Human Resource Management, 25, 2941-2956. 
Mehri, D. (2006). The darker side of lean: An insider's perspective on the realities of the Toyota production system. Academy of Management Perspectives, 20(2): 21-42.

Procter, S. (2001). Review of Delbridge (1998). The International Journal of Human Resource Management, 12, 1383-1384.

Procter, S., \& Currie, G. (2004). Target-based teamworking: Groups, work and interdependence in the UK civil service. Human Relations, 57, 1547-72.

Procter, S., \& Radnor, Z. (2014). Teamworking under lean in UK public services: Lean teams and team targets in Her Majesty's Revenue \& Customs (HMRC). The International Journal of Human Resource Management, 25, 2978-2995.

Sprigg, C., \& Jackson, P. (2006). Call centers as lean service environments: Job-related strain and the mediating role of work design. Journal of Occupational Health Psychology, $11,197-212$.

Sprigg, C., Stride, C., Wall, T., Holman, D., \& Smith, P. (2007). 'Work characteristics, musculoskeletal disorders, and the mediating role of psychological strain: A study of call center employees. Journal of Applied Psychology, 92, 1456-1466.

Sparrow, P., \& Otaye-Ebede, L. (2014). Lean management and HR function capability: The role of HR architecture and the location of intellectual capital. The International Journal of Human Resource Management, 25, 2892-2910.

Stanton, P., Gough, R., Ballardie, R., Bartram, T., Bamber, G., \& Sohal, A. (2014). Implementing lean management/six sigma in hospitals: Beyond empowerment or work intensification?. The International Journal of Human Resource Management, 25, 2926-2940.

Stewart, P., Richardson, M., Danford, A., Murphy, K., Richardson, T, \& Wass, V. (2009). We Sell our Time no More: Workers' Struggles Against Lean Production in the British Car Industry, London \& New York: Pluto Press.

Thirkell, E., \& Ashman, I. (2014). Lean towards learning: Connecting lean thinking and human resource management in UK higher education. The International Journal of Human Resource Management, 25, 2957-2977.

Treasury Select Committee (2011). Administration and Effectiveness of HMRC. http://www.publications.parliament.uk/pa/cm201012/cmselect/cmtreasy/731/73102.ht $\underline{\text { m. }}$.

Van den Broek, D., Callaghan, G., \& Thompson, P. (2004). Teams without teamwork? Explaining the call centre paradox. Economic and Industrial Democracy, $25,197-218$.

Vidal, M. (2007). Lean production, worker empowerment, and job satisfaction. Critical Sociology, 33, 247-278. 